Editorial

\title{
How our Scientific Society Contributes to a Better World
}

\section{Cómo Nuestra Sociedad Científica Contribuye a un Mundo Mejor}

\author{
Adolfo Galán ${ }^{1}$ \\ ${ }^{1}$ Presidente de la Sociedad Española de Cirugía de la Mano (SECMA) \\ Rev Iberam Cir Mano 2021;49(2):e89.
}

An essential pillar of our Society must be the promotion of research, undoubtedly the best guarantee of the progress of health systems. It is necessary to know what we do and the real results that patients obtain from our clinical actions. Only in this way will we achieve efficiency, so essential to make systems sustainable. It seems difficult to imagine that in the world of big data, in which we have so much immediate information, we are not able on many occasions to know if our actions have the desired purpose, and much less to know the impact of these in our patients, in their quality of life at a personal or work level, or in our Society. In general, this vast amount of data that we receive today continuously, in my opinion, misnamed instant information, can make us make mistakes because we do not know how to discriminate the quality and reliability of the sources. Moreover, the ease of diffusion can make us victims of vested interests. Could we then speak of instant disinformation?

Scientific societies should be a reference in transmitting neat, objective, and disinterested knowledge. We must be guarantors of the quality and independence of the training that we offer and receive. The development of implant and pathology registries as a source of knowledge will help to know what we are doing and what results we have. Teamwork and communication between professionals are necessary to obtain reliable data in the same way in different places and thus be able to speak the same language to make the appropriate analysis. It seems incredible that the health institutions and authorities have not taken the initiative and commissioned coordination in this regard. They have not complied with order SCO/3603/2003, of December 18, which creates the National Implant Registries ${ }^{1}$. The primary beneficiary will be the patient and, therefore, our Society and ourselves. From the SECMA, we will work so that all this develops as it should.

Training professionals based on a research culture will be the engine that pushes in the right direction. We have to achieve excellent quality and give it its due recognition. For this reason, professional accreditation is practically and objectively way endorsed by the scientific Society, and who knows if in the future by more institutions, it will be able to give it value. Creating and establishing a system of continuous improvement of our accreditation, thanks to the contributions of all the participants, will be one of the challenges for the coming years.

The use of new technologies and the seal of training quality of our Society can provide alternative sources of financing, so necessary at present to continue with this work, without having to affect the wallet of the partners.

We have a great opportunity in our common language to grow and communicate with other societies. Working together so that our Ibero-American Journal of Hand Surgery, which reflects our work, serves as an international standard, will be one of our priorities. I encourage you to collaborate on it since it reflects the great quality of your work.

\section{Reference}

1 «BOE» núm 309, de 26 de diciembre de 2003, páginas 46118 a 46118 (1 pág.). Available at https://www.boe.es/eli/es/o/ 2003/12/18/sco3603
Address for correspondence Adolfo Galán Novella, MD, Unidad de Miembro Superior y DOI https://doi.org/ Microcirugía, A.I.G. de Cirugía Ortopédica y Traumatología, Hospital Universitario Costa del Sol, Universidad de Málaga, Marbella, Spain (e-mail: agalann@hcs.es). 